The INL is a

U.S. Department of Energy

National Laboratory

operated by

Battelle Energy Alliance

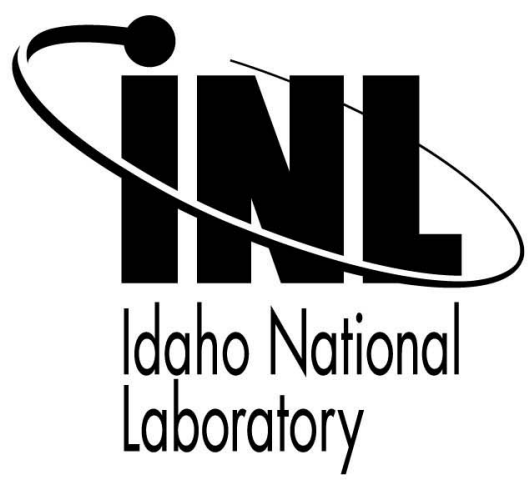

\title{
Real-Time Measurement of Material Elastic Properties in a High Gamma Irradiation Environment
}

\section{5th International Conference on NDE in Relation to Structural Integrity for Nuclear \& Pressurized Components}

R. S. Schley

K. L. Telschow

J. B. Walter

D. L. Cottle

\section{May 2006}

This is a preprint of a paper intended for publication in a journal or proceedings. Since changes may be made before publication, this preprint should not be cited or reproduced without permission of the author. This document was prepared as an account of work sponsored by an agency of the United States Government. Neither the United States Government nor any agency thereof, or any of their employees, makes any warranty, expressed or implied, or assumes any legal liability or responsibility for any third party's use, or the results of such use, of any information, apparatus, product or process disclosed in this report, or represents that its use by such third party would not infringe privately owned rights. The views expressed in this paper are not necessarily those of the United States Government or the sponsoring agency. 


\author{
R. S. SCHLEY,* K. L. TELSCHOW, J. B. WALTER, and D. L. COTTLE \\ Idaho National Laboratory, Physics Department, Idaho Falls, Idaho 83415-2209
}

This paper describes the first noncontact elastic vibration measurements of an object in a high gamma radiation field. Using a laser-coupled resonant ultrasound technique, the vibration modes of an Inconel hollow capped cylinder were measured as the gamma radiation field was increased to $10^{4} \mathrm{G} y / h$. This measurement technique allowed shifts in the resonant frequency of the sample's vibration modes to be tracked over a 170-h period. The vibration mode frequencies changed in a manner consistent with the temperature dependence of the elastic stiffness coefficients of the material. These results demonstrate the efficacy of the laser approach for real-time resonant ultrasound measurements in this severely hostile nuclear environment.

\section{INTRODUCTION}

Advances in nuclear reactor design are hindered by a paucity of materials property data for candidate structural materials, particularly at the higher projected operating temperatures and radiation doses. These data have been quite expensive to obtain, both in terms of reactor time to irradiate the specimens and in materials property testing. Currently, it is necessary to place many replicate samples in the reactor, remove one at the end of each desired interval, and measure its properties off-line, usually within a hot cell. This approach requires significant reactor time and operational interruptions, entails considerable personnel exposure to radiation, and creates radioactive waste. A better approach would be to place a single sample in the reactor for an extended period and

*E-mail: Robert.Schley@inl.gov measure its properties at the desired time intervals in situ and in real time. The goal of this work was to demonstrate the efficacy of making measurements on a sample in a high radiation environment and using these measurements to follow changes in the material properties as a function of irradiation time. Elastic measurements on an Inconel sample located in a high gamma radiation field, reported here, show changes in the material elastic stiffness due to radiation heating.

Acoustic nondestructive evaluation techniques have long been used to assess changes in industrial materials in less extreme environments. For instance, measurements have been reported on thermal aging/embrittlement in duplex stainless steels, ${ }^{1}$ residual stress in steel, ${ }^{2}$ and alteration of texture in aluminum ${ }^{3}$ and copper ${ }^{4}$ sheets. Ultrasonic wave propagation has been used to observe changes in dislocation densities in aluminum ${ }^{5}$ and $\mathrm{mi}-$ crostructure stability due to cold work of Ti-modified austenitic stainless steel and other materials of interest to the nuclear community. ${ }^{6}$ Vibrating sample internal friction measurements have identified the onset of plasticity in many materials. ${ }^{7}$ Recently, the acoustic method was used to measure properties of radioactive materials in a hot cell. 8

Through optical means, ultrasonic measurements can be noncontacting, offering the possibility of making measurements in high radiation fields. The technique, known as laser ultrasonics, optically generates and detects acoustic waves of all types. It requires no couplant or invasive sample preparation and uses the sample surface itself for transduction. Consequently, laser techniques are highly predictable and quantitative. Optical methods allow great control over the location of the measurement sites and their spatial and temporal absorbed intensity distribution. This allows measurements at virtually any frequency or acoustic wavelength of any specific elastic wave mode.

Optical generation and detection techniques are well documented. Bunkin, Kolomensky, and Mikhalevich ${ }^{9}$ and 
Gusev and Karabutov ${ }^{10}$ described the results of research on generation from laser sources of all types, primarily in metals and liquids. Scruby and Drain ${ }^{11}$ have compiled work on thermoelastic and ablation generation as well as the use of laser techniques for detection of all types of ultrasonic wave modes. Optical detection methods are based on time domain processing using homodyne, heterodyne, Fabry-Perot, ${ }^{12}$ and, more recently, photorefractive interferometry. ${ }^{13-15}$ At Idaho National Laboratory, all of these approaches are used for point measurements and imaging of acoustic motion under severe environmental conditions, such as sintering of ceramics ${ }^{16}$ and solidification of molten metals, ${ }^{17}$ and on materials with diffusely reflecting surfaces (e.g., paper). ${ }^{18}$ The high degree of predictability and absolute calibration afforded with optical techniques is unprecedented in acoustics, as transducer artifacts are virtually eliminated.

For the work reported here, an approach based on laser resonant ultrasound spectroscopy (LRUS) was selected. The transient pulse-echo measurement techniques described above are very useful for measuring material properties along a line between the source and detection points. But to get information on all of the elastic properties of a material, it is necessary to make measurements using multiple pairs of source-detector transducers at several locations. In contrast, resonant ultrasound spectroscopy (RUS) and LRUS simultaneously measure many modes, allowing determination of all of the elastic constants of the sample with a single measurement. Furthermore, modern computational methods allow accurate calculation of the resonant frequencies of samples in shapes of interest to the nuclear community. For a shape such as the hollow capped cylinder used in this study, the computation can be performed on a $\mathrm{PC}$ in a reasonable time.

This paper describes the first totally noncontacting RUS measurement of vibrations in a hollow capped Inconel cylinder located in a gamma radiation field of $10^{4}$ $\mathrm{Gy} / \mathrm{h}$. The design of the sample positioning and laser light delivery and collection apparatus are described. Results are reported for totally noncontacting remote measurements of a split vibration mode over the course of $170 \mathrm{~h}$ in the gamma radiation field.

\section{EXPERIMENTAL SETUP}

The Advanced Test Reactor (ATR) at Idaho National Laboratory has a gamma tube facility for high gamma radiation experiments. It consists of an empty vertical tube with a sealed bottom that is located near a fuel storage grid in the canal outside the reactor containment vessel. Fuel elements are loaded into the grid around the tube to provide the desired gamma radiation level.

For these experiments, a mechanical light pipe that allowed free space laser beam propagation was con- structed and installed in the gamma tube. Figure 1 shows the experimental layout.

Laser beams for generating and detecting ultrasonic waves in the sample were directed into the top of the light pipe and reflected by mirrors through free space to the bottom, $\sim 10 \mathrm{~m}$ from the laser equipment. At the bottom, a small concave mirror directed the source laser beam onto the sample surface and a parabolic mirror focused the detection laser beam onto the sample and collected the scattered light. Metallic mirrors rather than glass lenses were used to minimize radiation damage. Controls for sample positioning, including insertion and extraction from the tube, and for all mirror orientations were designed into the top of the light pipe.

The Inconel sample was a cylindrical tube, $-6.35 \mathrm{~mm}$ in diameter by $25.4 \mathrm{~mm}$ long, with welded end caps. Figure 2 shows a cutaway view of the sample in the holder. The holder contacted the sample at only three points in order to minimize vibrational constraints and allowed repeatable insertion and removal of the sample without repositioning the light pipe. A contact thermocouple monitored the temperature of the sample holder.

A pulsed Nd:YAG laser, producing $\sim 7 \mathrm{~ns}, 1 \mathrm{~mJ}$ pulses of $532 \mathrm{~nm}$ light at a repetition rate of 4 to $20 \mathrm{~Hz}$, was used for sample excitation. The excitation location could be positioned on the sample to optimize excitation for specific vibration modes.

An interferometric detection scheme suitable for an industrial setting was constructed using a continuous

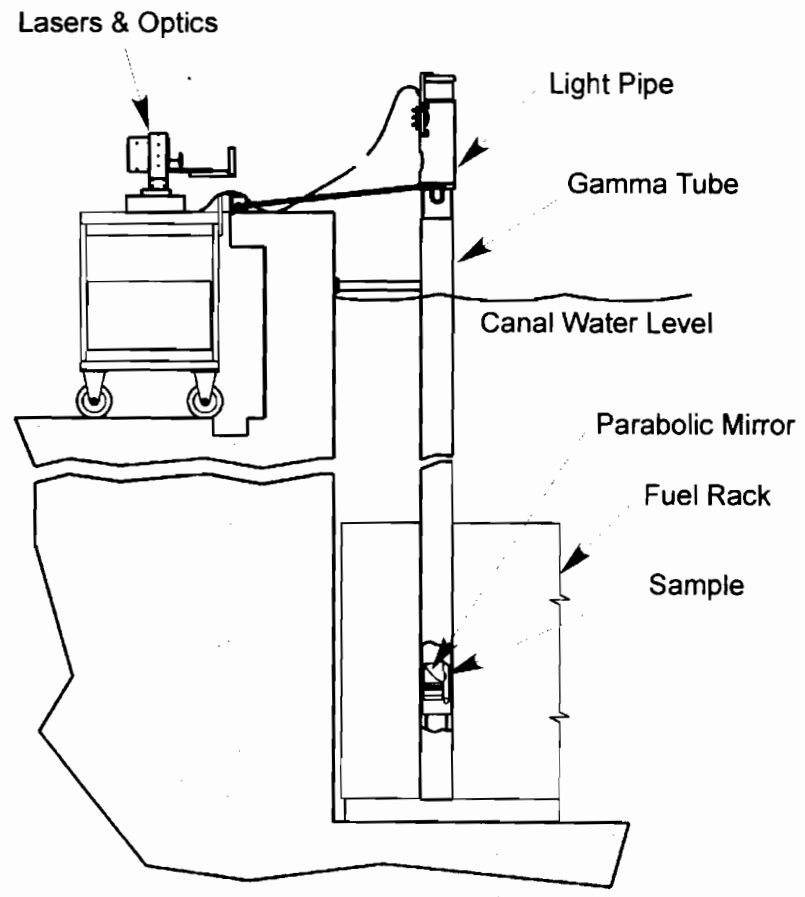

Fig. I. Diagram of the LRUS apparatus for measurements in the ATR ganma tube facility. 


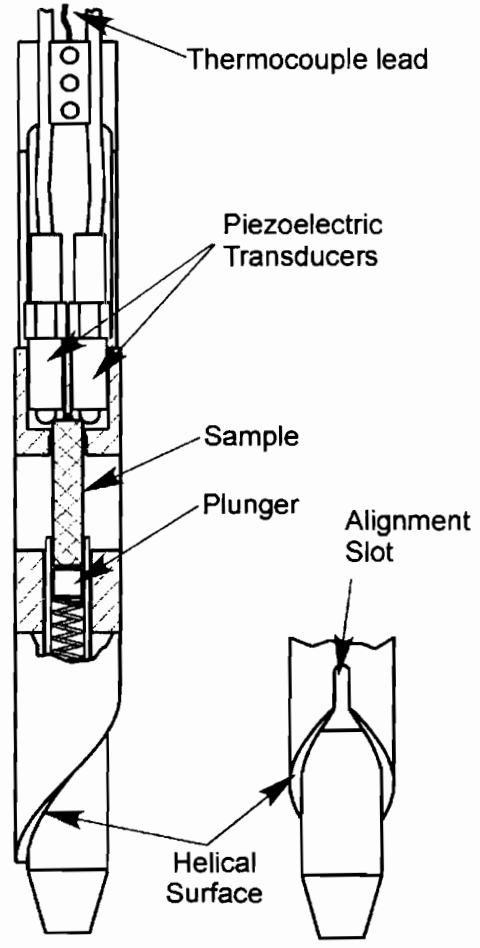

Fig. 2. Sample insertion holder that allowed automatic alignment of the sample within the focusing range of the excitation and detection laser beams.

Nd:YAG laser at $1064 \mathrm{~nm}$ and a high-speed photorefractive system to demodulate the reflected light. ${ }^{13}$ The system measured the ultrasonic normal displacement motion of the sample surface. The photorefractive interferometer used automatically adjusts for environmental vibrations, can form interference with diffuse or multiple speckle reflection from the rough sample surface, and does not require a stabilization feedback system. No adverse effects from environmental vibrations were observed, even though there was ongoing work in the canal area.

Piezoelectric transducers (source and detection) served as two of the contact points in the sample holder and aided in aligning the laser beams as well as providing redundant measurements. Although the two techniques, laser and piezoelectric, found several modes at the same frequencies, some modes were preferentially observed with one technique or the other because of different source and detector locations.

\section{LASER RESONANT ULTRASOUND SPECTROSCOPY MEASUREMENTS}

Transient motion was induced in the sample through the thermoelastic effect due to local heating. The excita- tion beam spot was large enough to avoid ablation. The resulting motion of the sample surface due to the vibration modes was recorded with a transient digitizer oscilloscope. Sample "ringing" was recorded for periods up to $200 \mathrm{~ms}$. Fourier transformation of the time sequence produced spectra of the vibration modes. Each laser pulse excited several different vibration modes. This can be seen in the spectrum from 40 to $150 \mathrm{kHz}$ obtained from the sample during the test and shown in Fig. 3. Figure 3 also shows the vibration frequencies calculated for the sample using the elementary XYZ basis function approach of Visscher et al. ${ }^{19}$ The mode notation is as follows: $A_{00}, A_{01}, \ldots$ are two-fold symmetric lateral squeezing modes; $\mathrm{A}_{10}, \mathrm{~A}_{11}, \ldots$ are three-fold lateral squeezing modes; $\mathrm{B}_{0}, \mathrm{~B}_{1}, \ldots$ are bending modes; $\mathrm{C}_{0}, \mathrm{C}_{1}$, $\ldots$ are longitudinal modes; and $T_{0}, T_{1}, \ldots$ are torsional twisting modes. The approximate noise level of the signal can be seen as the signal amplitude between the resonant peaks.

The $\mathrm{A}_{00}$ mode was monitored during this experiment. Figure 4 shows the spectrum of this mode in more detail before fuel was inserted around the gamma tube. This mode is actually split, most likely because of a slight asymmetry in the sample and the contact of the piezoelectric transducers at the top corner along a diagonal. These two resonances were tracked as they changed frequency during gamma irradiation.

At the start of the experiment, the radiation level was $\sim 90 \mathrm{~Gy} / \mathrm{h}$. The fuel elements were inserted in three steps (approximately one-third at each step). Both the temperature and resonance frequencies changed markedly as radiation heating increased the temperature and decreased the vibration mode resonant frequencies; see Fig. 5. The temperature rose and then leveled off after each fuel insertion. Equilibrium was reached after $\sim 1$ to $2 \mathrm{~h}$ when the heat flux due to radiation was balanced by
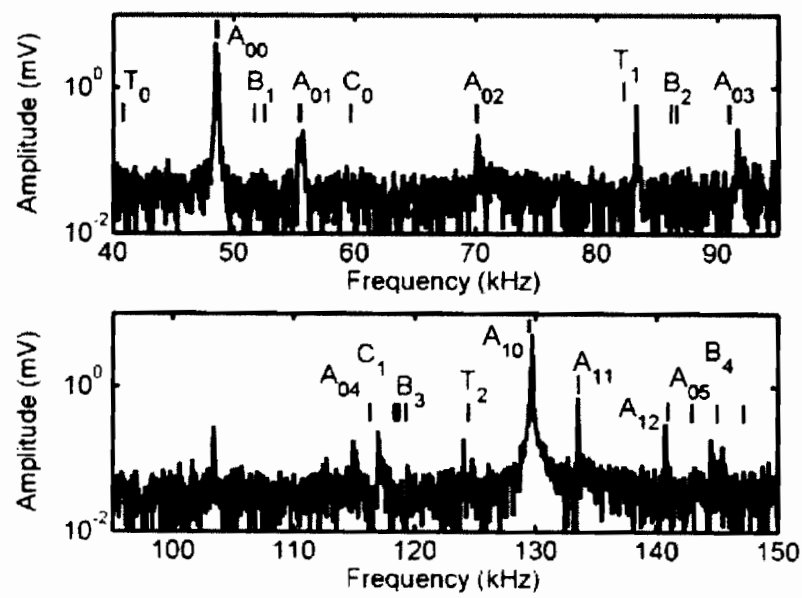

Fig. 3. Laser resonant ultrasound spectrum recorded from the cylindrical sample and the predicted modes. 


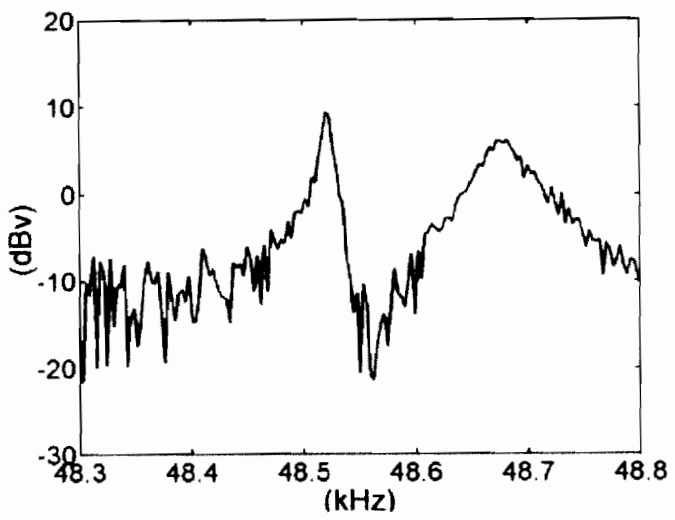

Fig. 4. Detail of spectrum of the lowest lateral squeezing $A_{00}$ mode that was monitored throughout the test.
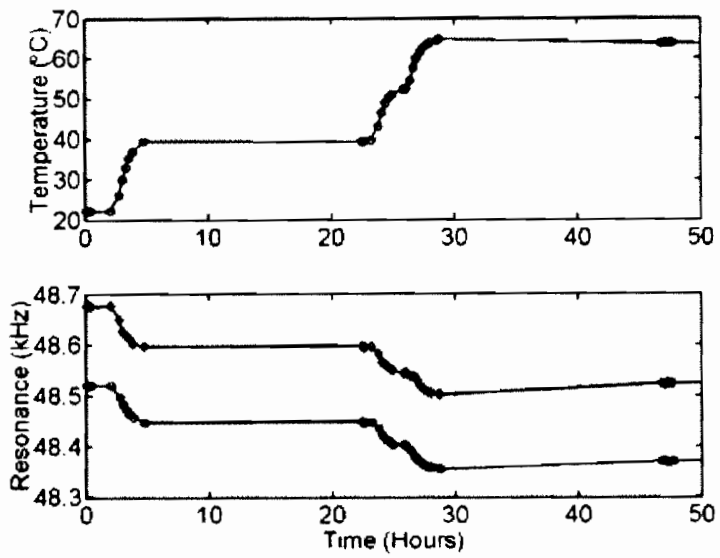

Fig. 5. Time history of the sample temperature and resonant frequencies for the split $\mathrm{A}_{(0)}$ mode. Equilibrium plateaus occur $\sim \mathrm{I}$ to $2 \mathrm{~h}$ after each fuel insertion.

the heat loss to the canal water. The temperature increased from $\sim 20^{\circ} \mathrm{C}$ to $\sim 65^{\circ} \mathrm{C}$ during the fuel insertions and subsequently decreased to $\sim 55^{\circ} \mathrm{C}$ as the radiation level decreased because of decay after $\sim 170 \mathrm{~h}$. The resonant mode frequencies decreased $\sim 200 \mathrm{~Hz}$, or $0.4 \%$, in a pattern that directly followed that of temperature. The measured radiation level was $>10^{4} \mathrm{~Gy} / \mathrm{h}$ at the end of the experiment.

The $A_{00}$ average mode frequency prior to irradiation was consistent with a Young's modulus of $179.0 \mathrm{GPa}$ and Poisson's ratio of 0.308 . These values, which compare well with published values ${ }^{20}$ of $177.3 \mathrm{GPa}$ and 0.31 at $21^{\circ} \mathrm{C}$ for Inconel 783 , were used to predict the resonant mode frequencies indicated in Fig. 3. Figure 6 shows the resonant frequency as a function of sample temperature for the entire experiment. The resonant mode frequencies decreased linearly with temperature, indicating that, as

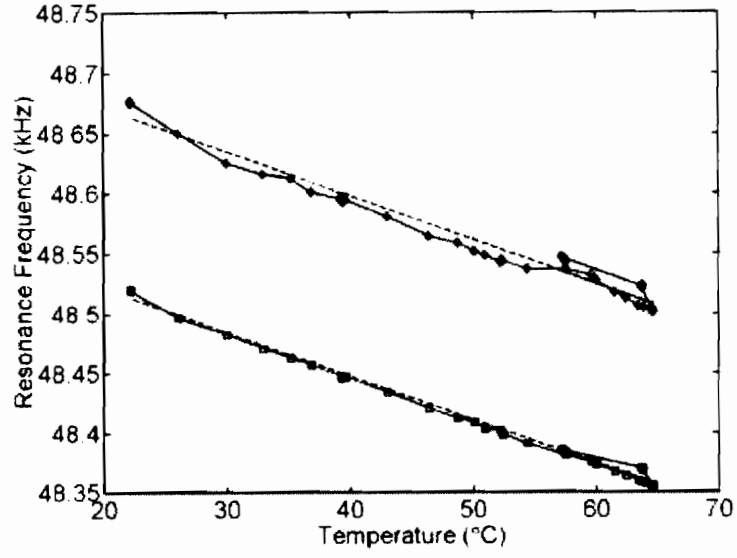

Fig. 6. Measured resonant mode frequencies as a function of sample temperature for $170 \mathrm{~h}$. The dotted lines are a linear fit to the data with a slope of $-3.7 \mathrm{~Hz} /{ }^{\circ} \mathrm{C}$ for the two modes.

expected, the changes were due principally to sample heating from the irradiation. Changes in resonant mode frequency occurred because of thermal expansion and the accompanying reduction in density and also because of elastic stiffness temperature dependence.

Modeling the $\mathrm{A}_{00}$ resonant mode frequency using only thermal expansion (coefficient of $\sim 1 \times 10^{-5}$ per ${ }^{\circ} \mathrm{C}$ ) and its density change indicates that this mode frequency should increase by $\sim 10 \mathrm{~Hz}$ over the temperature range incurred, contrary to the decrease we observed. However, when the model includes the changes in Young's modulus and the shear modulus (or Poisson's ratio) for Inconel 783 (Ref. 20), the predicted $\mathrm{A}_{00}$ resonant mode frequency decreases with temperature at $-4.8 \mathrm{~Hz} /{ }^{\circ} \mathrm{C}$, which is comparable to the experimental value of -3.7 $\mathrm{Hz} /{ }^{\circ} \mathrm{C}$. The origin of the discrepancy between the predicted and measured slope is unknown. Only the nominal data for Inconel 783 from Ref. 20 were used in the prediction; more detailed information concerning the temperature dependence of the elastic properties for this specific material sample would be required to provide a predicted value with higher confidence.

An interesting observation was that both mode frequencies increased by a small irreversible amount after $150 \mathrm{~h}$, as the sample began to cool. No opportunity existed to confirm this irreversible change in mode frequency, so one can only speculate that some sort of microstructural change occurred because of the gamma irradiation that increased the elastic constants by a small amount. Large changes in the microstructure due to gamma irradiation are not expected for a polycrystalline alloy, such as Inconel; however, such changes have been observed for single component materials, such as copper. ${ }^{21}$ Further research is necessary to establish the validity of this speculation; however, the results do illustrate the 
potential use of the laser acoustic approach for measuring, in situ, changes in material microstructure due to irradiation. It should also be noted that the signal from the piezoelectric transducers deteriorated substantially more than the LRUS signal during the course of the experiment.

\section{CONCLUSION}

Using a laser-based acoustic method, the mechanical properties of an object in a high gamma radiation field have been measured by a noncontacting technique for the first time. This demonstrated the ability of a laser excitation and detection technique to measure the acoustic vibrations of material parts, in situ to a high gamma radiation field and in real time. The frequency of a split vibration mode of an Inconel 783 capped tube was monitored over $170 \mathrm{~h}$ as the gamma radiation field was increased to $\sim 10^{4} \mathrm{~Gy} / \mathrm{h}$. Theoretical modeling of the $\mathrm{A}_{00}$ vibration mode predicted that the mode frequency would decrease with increasing temperature in a manner consistent with changes in the elastic moduli because of radiation heating of the material. Good agreement between the theoretical modeling and the physical measurements was obtained.

\section{ACKNOWLEDGMENT}

This work was sponsored by the U.S. Department of Energy through the INL Laboratory Directed Research and Development Program under DOE Idaho Operations Office Contract DE-AC07-99ID13727.

\section{REFERENCES}

1. M. BLASZKIEWICZ, "The Development of Nondestructive Evaluation (NDE) for Monitoring the Embrittlement in Nuclear Reactor Pressure Vessels," Nondestructive Characterization of Materials VII. A. L. BATROS, R. E. GREEN. and C. O. RUUD, Eds., Part 1, pp. 9-15, Transtec Publications. Ltd., Lebanon, New Hampshire (1996).

2. T. BERRUTI and M. M. GOLA, "Acoustoelastic Determination of Stresses in Steel Using Rayleigh Ultrasonic Waves," Nondestructive Characterization of Materials VII, A. L. BATROS, R. E. GREEN, and C. O. RUUD, Eds., Part I, pp. 171178, Transtec Publications, Ltd., Lebanon, New Hampshire (1996).

3. E. SCHNEIDER and L. OESTERLEIN, "Ultrasonic Characterization of Texture in Aluminum Rolled Products," Nondestructive Characterization of Materials VII, A. L. BATROS, R. E. GREEN, and C. O. RUUD, Eds., Part 1, pp. 405-410, Transtec Publications Ltd., Lebanon, New Hampshire (1996).
4. G. A. AHLERS. P. PURTSCHNER, J. F. BREEDIS, and F. N. MANDIGO. "Monitoring of Texture Development in Copper-Alloy Sheet," Nondestructive Characterization of Materials VIII, R. E. GREEN, Ed., pp. 189-195, Plenum Press, New York (1998).

5. W. JOHNSON, "Ultrasonic Damping and Velocity during Recovery and Recrystallization of Aluminum," Nondestructive Characterization of Materials VIII, R. E. GREEN, Ed., pp. 145150. Plenum Press, New York (1998).

6. M. VASUDEVAN and P. PALANICHAMY, "Assessment of Microstructure Stability of Cold Worked Ti-Modified Austenitic Stainless Steel During Aging Using Ultrasonic Velocity Measurements and Correlation with Mechanical Properties," J. Nucl. Mater., 312, 181 (2003).

7. A. B. LEBEDEV, "Amplitude-Dependent Damping and Acoustoplastic Effect in Crystals," Nondestructive Characterization of Materials VIII, R. E. GREEN, Ed., pp. 519-526, Plenum Press, New York (1998).

8. T. ISHII, N. OOKA, T. HOSHIYA, H. KOBAYASHI. J. SAITO, M. NIIMI, and H. TSUJI. "Development of a NonDestructive Testing Technique Using Ultrasonic Wave for Evaluation of Irradiation Embrittlement in Nuclear Materials," J. Nucl. Mater, 307-311, 240 (2002).

9. F. V. BUNKIN, AL. A. KOLOMENSKY, and V. G. MIKHALEVICH, Lasers in Acoustics. Harwood Academic Press, Philadelphia (1990).

10. V. E. GUSEV and A. A. KARABUTOV, Laser Optoacoustics, AIP Press, New York (1993).

11. C. B. SCRUBY and L. E. DRAIN, Laser Ultrasonics, Techniques and Applications. Adam Hildger Publishing Company, New York (1988).

12. J. W. WAGNER, Physical Acoustics, Vol. XIX, R. N. THURSTON and A. D. PIERCE. Eds., Chap. 5, Academic Press. New York (1990)

13. R. K. ING and J.-P. MONCHALIN. "Broadband Optical Detection of Ultrasound by Two-Wave Mixing in a Photorefractive Crystal," Appl. Phys. Lett., 59, 3233 (1991).

14. R. S. SCHLEY, K. L. TELSCHOW. and J. HOLLAND, "Static and Dynamic Two-Wave Mixing in GaAs," Appl. Opt., 39, 24, 4348 (Aug. 20, 2000).

15. E. F. LAFOND, P. H. BRODEUR, J. P. GERHARDSTEIN, C. C. HABEGER, J. H. JONG, and K. L. TELSCHOW, "Photorefractive Interferometers for Ultrasonic Measurements on Paper," Ultrasonics, 40, 1019 (2002).

16. K. L. TELSCHOW, J. B. WALTER, and G. V. GARCIA. "Laser Ultrasonic Monitoring of Ceramic Sintering," J. Appl. Plivs., 68, 12, 6077 (1990).

17. J. B. WALTER, K. L. TELSCHOW, and R. E. HAUN, "Laser Acoustic Molten Metal Depth Sensing in Titanium," Advanced Sensors for Metals Processing, B. W. BRUSEY, J. F. 
BUSSIÈRE, M. DUBOIS, and A. MOREAU. Eds.. pp. 265274. Canadian Institute of Mining, Metallurgy and Petroleum. Montreal, Quebec (1999).

18. O. MUKDADI, S. K. DATTA, K. L. TELSCHOW, and V. A. DEASON. "Ultrasonic Guided Waves in Thin Orthotropic Layers: Theoretical Analysis and Dynamic Holographic Imaging Measurement," IEEE Trans. Ultrason., Ferroelect., Freq. Contr.. 48, 6. 1581 (2001).

19. W. M. VISSCHER, A. MIGLIORI, T. M. BELL, and R. A. REINERT, "On the Normal Modes of Free Vibration of Inho- mogeneous and Anisotropic Objects," J. Acoust. Soc. Am., 90, 2154 (1991).

20. "Inconel Alloy 783 Data Sheet" from Special Metals Co.. 3200 Riverside Drive Huntington, WV 25705-1771; available on the Internet at www.specialmetals.com.

21. D. O. THOMPSON and D. K. HOLMES, "The Effect of Gamma Irradiation on the Young's Modulus of Copper," J. Phys. Chem. Solids, 1, 275 (1957). 